\title{
Papers
}

\section{Stepping down inhaled corticosteroids in asthma: randomised controlled trial}

\author{
Gillian Hawkins, Alex D McMahon, Sara Twaddle, Stuart F Wood, Ian Ford, Neil C Thomson
}

\begin{abstract}
Objectives To determine whether the dose of inhaled corticosteroids can be stepped down in patients with chronic stable asthma while maintaining control. Design One year, randomised controlled, double blind, parallel group trial.

Setting General practices throughout western and central Scotland.

Participants 259 adult patients with asthma receiving regular treatment with inhaled corticosteroids at high dose (mean dose $1430 \mu \mathrm{g}$ beclomethasone dipropionate).

Interventions Participants were allocated to receive either no alteration to their dose of inhaled corticosteroid (control) or a 50\% reduction in their dose if they met criteria for stable asthma (stepdown). Main outcome measures Comparison of asthma exacerbation rates, asthma related visits to general practice and hospital, health status measures, and corticosteroid dosage between the two groups.

Results The proportions of subjects with asthma exacerbations were not significantly different (stepdown 31\%, control 26\%, P=0.354). Similarly, the numbers of visits to general practice or hospital and the disease specific and generic measures of health status over the one year period were not significantly different. On average the stepdown group received $348 \mu \mathrm{g}(95 \%$ confidence interval $202 \mu \mathrm{g}$ to $494 \mu \mathrm{g})$ of beclomethasone dipropionate less per day than the controls (a difference of $25 \%$ ), with no difference in the annual dose of oral corticosteroids between the two treatment regimens.
\end{abstract}

Conclusions By adopting a stepdown approach to the use of inhaled steroids at high doses in asthma a reduction in the dose can be achieved without compromising asthma control.

\section{Introduction}

Inhaled corticosteroids are highly effective in the treatment of asthma. ${ }^{1-3}$ Their potential for causing dose related side effects has, however, led to asthma management guidelines recommending a reduction in their dose once asthma control is established. ${ }^{2-4}$ Research evidence shows that a reduction can be achieved in the short term, in mild disease, or with the addition of other antiasthma treatments. ${ }^{5-8}$ The clinical implications of this approach to treatment have not, however, been tested by means of a randomised controlled trial over the longer term or for patients with moderate to severe disease. We therefore tested the hypothesis that a stepdown approach to the use of inhaled corticosteroids at high dosage can be adopted safely in adults with chronic stable asthma.

\section{Methods \\ Participants}

We recruited 259 participants from general practices throughout western and central Scotland. Participants were aged 18 years and older, had a diagnosis of asthma $^{9}$ for at least one year, and were being treated with at least $800 \mu \mathrm{g}$ inhaled beclomethasone dipropionate daily (or budesonide or fluticasone propionate at equivalent dosage). We excluded patients if they had required oral corticosteroids or visited general practice or hospital for asthma in the preceding two months. Other exclusion criteria included inability to use a peak flow meter; treatment with immunosuppressive drugs; serious illness; alcohol, drug, or substance misuse; pregnancy; and participation in other research in the past six months. Participants gave written informed consent.

\section{Study design}

We conducted a multicentre, randomised, double blind, parallel group trial over a period of one year.

\section{Protocol, assignment, and masking}

Run-in-We collected baseline data during a one month run-in period. Before run-in, we allocated participants a dose of beclomethasone dipropionate (metered dose inhaler) or fluticasone propionate (metered dose inhaler or dry powder inhaler; Accuhaler, GlaxoSmithKline, Middlesex, United Kingdom) according to their use of inhaled corticosteroids before the study. A spacer device (Volumatic, GlaxoSmithKline, Middlesex, United Kingdom) was provided for patients using a metered dose inhaler.

Randomisation visit-After run-in, we used a computer generated allocated randomisation sequence, stratified by centre, to randomise participants to either a reduction in their dose of inhaled corticosteroid (stepdown) or a sham reduction (control). Randomisation numbers were issued on a sequential basis, and the randomisation code was withheld from the investigators until completion of the study.
Department of General Practice, University of Glasgow, Glasgow G12 0RR

Gillian Hawkins clinical research fellow Stuart F Wood senior lecturer

Robertson Centre for Biostatistics, University of Glasgow, Glasgow G12 8QQ Alex D McMahon senior statistician Ian Ford

Department of Research and Development, Stobhill Hospital, Glasgow G21 3UT Sara Twaddle head of research and development

Department of Respiratory

Medicine,

University of Glasgow, Western Infirmary, Glasgow G11 6NT

Neil C Thomson professor

Correspondence to: N C Thomson n.c.thomson@ clinmed.gla.ac.uk

bmj.com 2003;326:1115 


\section{Study inhaler packs}

We allocated all participants to a starting dose of inhaled corticosteroid according to their use of inhaled corticosteroids before the study - for example, $1000 \mu \mathrm{g}$ beclomethasone dipropionate. Starting doses of inhaled corticosteroids were allocated from beclomethasone dipropionate $(1000 \mu \mathrm{g}, 1500 \mu \mathrm{g}$, or $2000 \mu \mathrm{g}$ daily) or fluticasone propionate $(500 \mu \mathrm{g}$, $1000 \mu \mathrm{g}, 1500 \mu \mathrm{g}$, or $2000 \mu \mathrm{g}$ daily). Study inhaler packs were then made up for each participant according to which treatment they had been allocated to as follows.

\section{Stepdown group}

Usual dose pack: contains the starting dose of inhaled corticosteroid-for example, $1000 \mu \mathrm{g}$ beclomethasone dipropionate

Reduced dose pack: contains $50 \%$ of the starting dose of inhaled corticosteroid-for example, $500 \mu \mathrm{g}$ beclomethasone dipropionate

\section{Control group}

Usual dose pack: contains the starting dose of inhaled corticosteroid

Reduced dose pack: contains the starting dose of inhaled corticosteroid

Study inhalers-A central pharmacy produced two packs of inhaled corticosteroid for each participant according to the randomisation code. The packs were identical in appearance and labelled either "usual dose" or "reduced dose" (box).

Study visits-At randomisation, participants received a pack containing inhaled corticosteroids at usual dosage. Subsequent study visits took place at three, six, nine, and 12 months, when asthma control was assessed and an inhaler pack issued accordingly (good control=reduced dose, poor control=usual dose). Thus the dosage of inhaled corticosteroid remained unaltered in the control group, and in the stepdown group it went down or up according to asthma control.

\section{Assessment of asthma control}

Patients kept diaries of their peak expiratory flow during run-in and for two weeks before each study visit. Measurements were made morning and evening (Mini-Wright peak flow meter, Clement Clarke, Harlow, United Kingdom) and the best of three attempts recorded. A "target" peak flow was calculated for each participant, defined as $80 \%$ of the mean peak flow during run-in.

We calculated a short asthma morbidity score at each visit. ${ }^{10}$ This was derived from a four item questionnaire relating to asthma symptoms and use of a reliever inhaler over the preceding month. Scores ranged from 0 (perfect control) to 8 (very poor control).

Study criteria for good control were an asthma morbidity score of 2 or less, no visits for asthma to general practice or hospital since the previous visit, and a peak flow greater than or equal to the "target" peak flow on eight of the past 14 days. If peak flow data were not available we used the first two criteria.

\section{Management of worsening asthma}

Participants were advised to use their reliever inhaler on a regular basis and to seek medical attention if symptoms failed to settle or their peak flow dropped to below $70 \%$ of the mean run-in peak flow. The attending doctor treated exacerbations with a course of oral corticosteroids as considered necessary.

\section{Objectives and outcome measures}

The primary objective was to compare between the two groups the proportion of participants who had an exacerbation of their asthma. Secondary objectives were to determine in the stepdown group the proportion of participants achieving a $50 \%$ reduction in their daily dose of inhaled corticosteroids while maintaining asthma control, and to compare between the two groups the number of asthma related events, the total dose of inhaled and oral corticosteroid administered, and any changes in health status over the one year period.

An asthma exacerbation was defined as any worsening of asthma requiring a course of oral corticosteroids. Asthma related events were defined as any admission to hospital, attendance at accident and emergency departments, visit to general practice, or home visit by the general practitioner, with worsening asthma. Details of asthma events were confirmed through general practice records. Details of courses of oral corticosteroid and any use of additional inhaled corticosteroids, or "doubling up" of study inhalers were recorded. Participants graded compliance with study inhalers on a scale of 1 (poor) to 10 (excellent). ${ }^{11}$

Participants completed two measures of health status, the St George's respiratory questionnaire and EuroQol, at each visit. ${ }^{12}{ }^{13}$ A score measuring the impact of chest disease on daily life and wellbeing was derived from the St George's respiratory questionnaire. This ranged from 0 (minimum impact) to 100 (maximum impact). The EuroQol is a generic measure of health related quality of life, including a visual analogue scale, ranging from 0 (worst imaginable health state) to 100 (best imaginable health state).

Forced expiratory volume in one second $\left(\mathrm{FEV}_{1}\right)$ and forced vital capacity (FVC) were measured before and after administration of inhaled salbutamol $(200 \mu \mathrm{g}$ from a volumatic spacer) by using a dry spirometer (Vitalograph, Buckinghamshire, United Kingdom), and the best of three attempts was recorded.

\section{Analysis}

We estimated that $15 \%$ of patients with well controlled asthma might be expected to experience an exacerbation of asthma over a one year period. ${ }^{14}{ }^{15}$ We aimed to recruit 120 patients per group, to give the trial $80 \%$ power at a significance level of $5 \%$ to detect a clinically relevant difference in exacerbation rate of $15 \%$ between the two groups.

We collected data regarding asthma exacerbations, asthma related events, and use of oral corticosteroids for all participants for the full one year period and performed intention to treat analyses. Analysis of inhaled corticosteroid use and health status was limited to patients who had complete data for at least one visit after randomisation.

We used the $\chi^{2}$ test to analyse asthma exacerbations and asthma events, with corresponding odds ratio and $95 \%$ confidence interval. We carried out a subgroup analysis of asthma exacerbations after excluding participants receiving treatment with long acting $\beta_{2}$ 
agonists. We used a Wilcoxon test to compare use of oral corticosteroids between the two groups.

We calculated an annual dose of inhaled corticosteroids for each participant and expressed this in units of beclomethasone dipropionate (by using a conversion rate of $2 \mathrm{mg}$ beclomethasone dipropionate $=1 \mathrm{mg}$ fluticasone propionate). Where participants were withdrawn before completing one year follow up we calculated an annual equivalent dose from the average daily dose. We used a $t$ test and 95\% confidence interval for the difference of two means for analysis.

For the St George's respiratory questionnaire, the short asthma morbidity score, and the EuroQol visual analogue scale we expressed the worst score recorded during follow up as a change from baseline and compared scores between the two groups by using a $t$ test and 95\% confidence interval for difference in means.

\section{Results}

Between May 1999 and October 2001 we randomised 259 participants (aged 18 to 86 years) to the trial, and $212(82 \%)$ completed one year follow up. We analysed data from all patients for the primary outcome (figure). The groups were similar with regard to baseline demographics and clinical characteristics (table 1). Altogether 109/130 (84\%) of the stepdown group and $105 / 129(81 \%)$ of the control group met criteria for good control, and these were issued with a "reduced dose" pack of inhaled corticosteroids at some point during the study. Sixty four (49\%) participants in the stepdown group completed the study taking a reduced dose of inhaled corticosteroid (50\% of starting dose) and with good control. Both groups reported good compliance with study inhalers (mean score 10/10).

\section{Asthma exacerbations and asthma related events}

We found no significant difference in the rate of asthma exacerbation or asthma events between the two groups (table 2). Forty participants (31\%) of the stepdown group and $33(26 \%)$ of the control group experienced at least one asthma exacerbation over the one year period (odds ratio 1.29, 95\% confidence interval 0.75 to $2.23, \mathrm{P}=0.354$ ). A visit to general practice was the most common event to occur in both groups (stepdown 35\% (45 participants), control group $32 \%$ (41 participants); odds ratio $1.14,0.68$ to 1.91 , $\mathrm{P}=0.629)$. Home visits, attendances in accident and emergency wards, and admissions to hospital were rare events in both groups.

Health status measures and short asthma morbidity score

The differences between the two groups in the mean change in score from baseline were not significantly different for the St George's respiratory questionnaire (difference $0.13,95 \%$ confidence interval -2.76 to $3.03, \mathrm{P}=0.929)$, the short asthma morbidity score $(0.16$, -0.34 to $0.66, \mathrm{P}=0.537$ ), or the EuroQol visual analogue scale $(2.32,-1.67$ to $6.32, \mathrm{P}=0.252)$ (table 3$)$.

\section{Annual corticosteroid dose}

Table 4 shows data on use of inhaled corticosteroids for 243 participants (stepdown 120, control 123). We found a significant difference in the mean annual dose of inhaled corticosteroid between the two groups (stepdown $390 \mathrm{mg}$ beclomethasone dipropionate, control $517 \mathrm{mg}$ beclomethasone dipropionate, $\mathrm{P}<0.001$; mean difference $-127 \mathrm{mg},-180$ to -74 ). This represents a mean daily saving of $348 \mu \mathrm{g}$ of beclomethasone dipropionate for participants in the stepdown group (95\% confidence interval 202 to 494). We found no significant difference in the mean annual dose of oral corticosteroid (prednisolone) between the two groups (stepdown 117 mg, control 109 mg; $\mathrm{P}=0.252$ ).

Adverse events-Fourteen participants (seven in each group) experienced a serious adverse event during the study, and three events were asthma related. These three events occurred in the stepdown group and were all non-fatal asthma exacerbations requiring admission to and treatment in hospital. Of the three participants experiencing an asthma related adverse event, only one was taking a reduced dose of inhaled corticosteroid at the time of the event whereas the dose of the other two had not been reduced at any time before the event.

\section{Discussion}

Our study provides evidence that, by using the procedure outlined, adopting a stepdown approach to

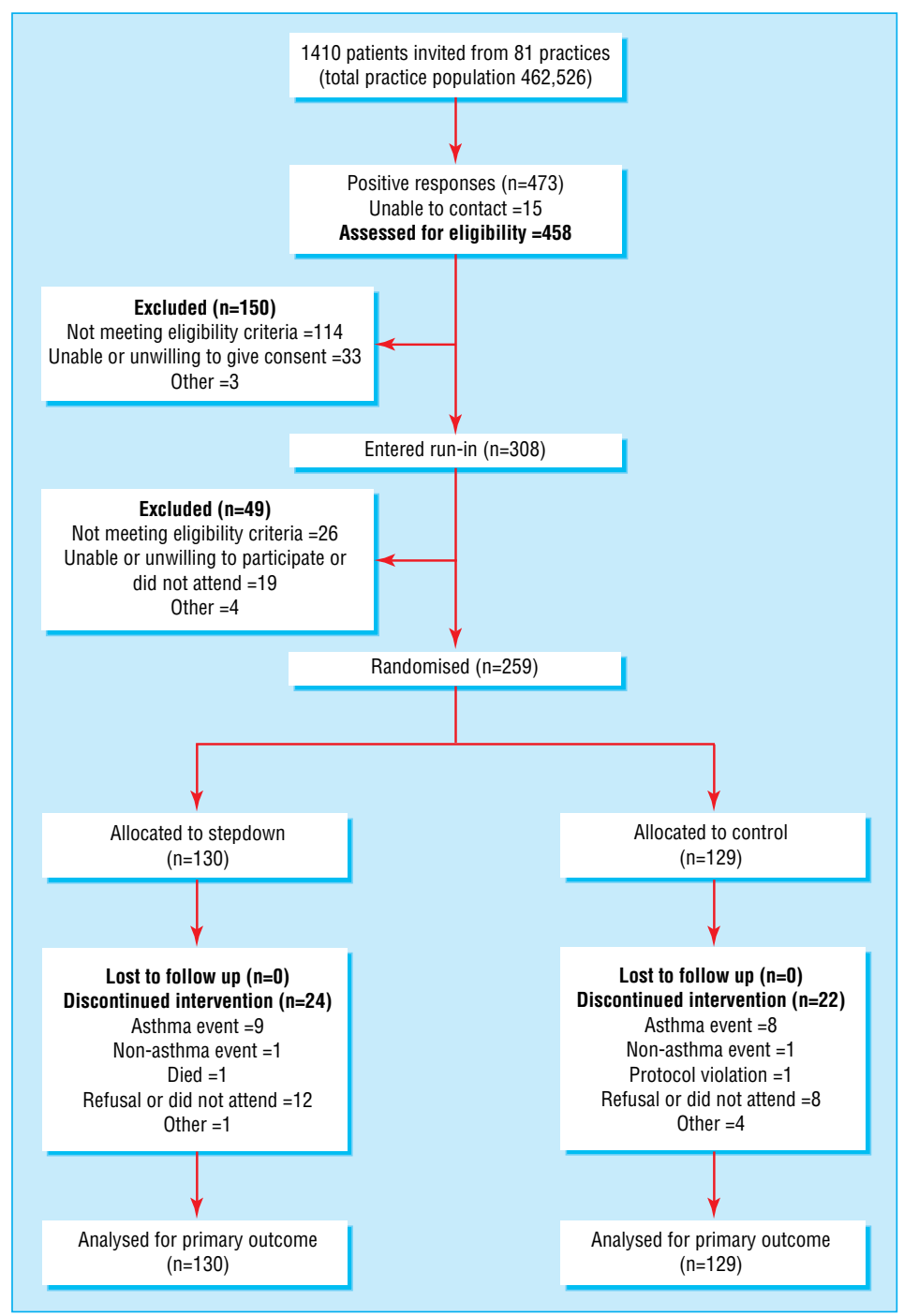

Flow of participants 
Table 1 Baseline characteristics of the two groups in the randomised controlled trial. Values are numbers (\%) of patients unless otherwise indicated

\begin{tabular}{|c|c|c|}
\hline Characteristic & $\begin{array}{l}\text { Stepdown group } \\
(\mathrm{n}=\mathbf{1 3 0})\end{array}$ & $\begin{array}{l}\text { Control group } \\
(n=129)\end{array}$ \\
\hline Age in years (SD) & $52.8(14.5)$ & $55(15.2)$ \\
\hline \multicolumn{3}{|l|}{ Sex: } \\
\hline Male & $54(41.5)$ & $54(41.9)$ \\
\hline Female & $76(58.5)$ & $75(58.1)$ \\
\hline \multicolumn{3}{|l|}{ Smoking status: } \\
\hline Current smoker & $16(12.3)$ & $17(13.2)$ \\
\hline Former smoker & $44(33.8)$ & $49(38.0)$ \\
\hline Never smoker & $70(53.9)$ & $63(48.8)$ \\
\hline Duration of asthma in years (SD) & $19(14.9)$ & $19(16.4)$ \\
\hline \multicolumn{3}{|l|}{ Run-in daily dose of inhaled corticosteroid } \\
\hline \multicolumn{3}{|l|}{ Beclomethasone dipropionate: } \\
\hline $1000 \mu \mathrm{g}$ & $53(40.8)$ & $71(55.0)$ \\
\hline $1500 \mu \mathrm{g}$ & $10(7.7)$ & $5(3.9)$ \\
\hline $2000 \mu \mathrm{g}$ & $4(3.1)$ & $5(3.9)$ \\
\hline \multicolumn{3}{|l|}{ Fluticasone propionate: } \\
\hline $500 \mu \mathrm{g}$ & $22(16.9)$ & $12(9.3)$ \\
\hline $1000 \mu \mathrm{g}$ & $34(26.2)$ & $30(23.3)$ \\
\hline $1500 \mu \mathrm{g}$ & $4(3.1)$ & $4(3.1)$ \\
\hline $2000 \mu \mathrm{g}$ & $3(2.3)$ & $2(1.6)$ \\
\hline $\begin{array}{l}\text { Daily baseline dose }(\mu \mathrm{g}) \text { of inhaled corticosteriod as } \\
\text { beclomethasone equivalent }(\mathrm{SD})\end{array}$ & $1461.5(657.7)$ & $1399.2(623.1)$ \\
\hline \multicolumn{3}{|l|}{ Other antiasthma medication: } \\
\hline Long acting $\beta_{2}$ agonist & $48(36.9)$ & $39(30.2)$ \\
\hline Leukotriene receptor antagonist & $5(3.9)$ & $4(3.1)$ \\
\hline Theophylline & $12(9.2)$ & $10(7.8)$ \\
\hline Anticholinergic & $8(6.15)$ & $12(9.3)$ \\
\hline \multicolumn{3}{|l|}{ Respiratory function: } \\
\hline Target peak expiratory flow ( $\mathrm{n}=239$ ) in litres/minute (SD) & $324(84.6)$ & $314(81.4)$ \\
\hline Pre-salbutamol $\mathrm{FEV}_{1}(\mathrm{n}=257)$ as $\%$ of predicted value (SD) & $80.3(19.2)$ & $80.1(18.6)$ \\
\hline Post-salbutamol FEV ${ }_{1}(\mathrm{n}=257)$ as $\%$ of predicted value (SD) & $85.5(18.4)$ & $85.3(17.9)$ \\
\hline \multicolumn{3}{|l|}{ Health status measures: } \\
\hline Short asthma morbidity score (SD) & $1.1(1.3)$ & $1.2(1.3)$ \\
\hline St George's respiratory score $(n=254)(S D)$ & $24.7(16.8)$ & $25.0(16.4)$ \\
\hline EuroQol visual analogue scale $(n=237)(S D)$ & $76.8(14.5)$ & 73 (16.8) \\
\hline
\end{tabular}

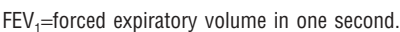

inhaled corticosteroids is safe in patients with stable asthma who receive regular treatment with at least $1000 \mu \mathrm{g}$ beclomethasone dipropionate daily. This is an important finding as it supports the recommendations made in current asthma guidelines and can be used to inform future evidence based practice.

Inhaled corticosteroids are widely accepted as the treatment of choice for patients with chronic asthma. ${ }^{1-3}$
However, they have been associated with a number of dose related side effects including bruising, cataract formation, glaucoma, reduced bone density, and adrenal suppression. ${ }^{14^{16}}$ The therapeutic response may plateau at doses below $1000 \mu \mathrm{g}$ of inhaled beclomethasone dipropionate (500 $\mu \mathrm{g}$ of fluticasone propionate), ${ }^{17-19}$ and it should therefore be possible for a substantial proportion of patients receiving inhaled corticosteroids at high dosage to reduce their dose, thereby reducing the risk of side effects while maintaining control.

\section{Limitations of the study}

Inhaled long acting $\beta_{2}$ agonist have been shown to facilitate a reduction of inhaled corticosteroids in asthma patients. ${ }^{78}$ In our study $48(37 \%)$ participants in the stepdown group and $39(30 \%)$ controls were receiving regular treatment with these drugs. A subgroup analysis after these patients were excluded did not show a significant difference between the two groups for the main outcome measure of asthma exacerbation ( $34 \%$ versus $24 \%, \mathrm{P}=0.148$ ). However, owing to the smaller numbers the power of this analysis to detect a clinically significant difference would have been reduced. A much larger study would be required to tease out the effects, if any, that polypharmacy might have on stepping down inhaled corticosteroids.

We compared two management strategies for inhaled corticosteroid use in asthma: a "do nothing" approach, where the dose of inhaled steroid remained unaltered over the one year period, and a "stepdown" approach, where the dose was reduced by $50 \%$ only if criteria for asthma stability were met. The differences between the two strategies in the rate of asthma exacerbations or general practice visits or in measures of health related quality of life were non-significant. We also found no significant differences in home visits, attendances at accident and emergency departments, or hospital admissions; as these were rare events for both groups, however, a larger study would be required to provide sufficient power to detect a difference in the rate of these outcomes.

It is possible that inclusion in a trial leads to improved compliance with medications. If one assumes this to have been the case in our study then a degree of caution should be adopted in translating our experience to the clinical setting.

Table 2 Asthma exacerbations and asthma related events in the two groups. Values are numbers (\%) of patients

\begin{tabular}{|c|c|c|c|c|}
\hline & $\begin{array}{l}\text { Stepdown group } \\
\qquad(\mathrm{n}=130)\end{array}$ & $\begin{array}{l}\text { Control group } \\
(\mathrm{n}=129)\end{array}$ & $\begin{array}{l}\text { Odds ratio } \\
(95 \% \mathrm{Cl})\end{array}$ & $\begin{array}{l}\text { P value } \\
\left(\chi^{2} \text { test }\right)\end{array}$ \\
\hline Asthma exacerbations & $40(31)$ & $33(26)$ & $1.29(0.75$ to 2.23$)$ & $\mathrm{P}=0.354$ \\
\hline \multicolumn{5}{|l|}{ Asthma related events: } \\
\hline Visit to general practice & $45(35)$ & $41(32)$ & $1.14(0.68$ to 1.91$)$ & $\mathrm{P}=0.629$ \\
\hline Home visit by general practitioner & $3(2)$ & $6(5)$ & $0.48(0.12$ to 1.98$)$ & $\mathrm{P}=0.304$ \\
\hline Visit to accident and emergency department & $2(2)$ & $1(1)$ & $2(0.18$ to 22.3$)$ & $P=0.567$ \\
\hline Admission to hospital & $4(3)$ & $1(1)$ & 4.06 (0.45 to 36.86$)$ & $P=0.179$ \\
\hline
\end{tabular}

Table 3 Health status of the two groups as measured by validated instruments and short asthma morbidity score

\begin{tabular}{lcccc} 
& Stepdown group & Control group & Difference (95\% Cl) & P value $(\boldsymbol{t}$ test) \\
\hline St George's respiratory questionnaire & $(\mathrm{n}=110)$ & $(\mathrm{n}=119)$ & & \\
\hline Difference of maximum score from baseline (SD) & $7.53(10.68)$ & $7.40(11.95)$ & $0.13(-2.76$ to 3.03$)$ & \\
\hline Short asthma questionnaire morbidity score & $(\mathrm{n}=120)$ & $(\mathrm{n}=122)$ & $0.16(-0.34$ to 0.66$)$ & \\
\hline Difference of maximum score from baseline $(\mathrm{SD})$ & $1.59(1.96)$ & $1.43(2.00)$ & & $\mathrm{P}=0.929$ \\
\hline EuroQol & $(\mathrm{n}=108)$ & $(\mathrm{n}=111)$ & $2.32(-1.67$ to 6.32$)$ & $\mathrm{P}=0.537$ \\
\hline Difference of lowest score from baseline $(\mathrm{SD})$ & $-7.00(13.04)$ & $-9.32(16.69)$ &
\end{tabular}




\section{Strengths of the study}

This was a pragmatic trial with a complex intervention. ${ }^{20}$ We enrolled patients typical of those managed in primary care and used outcome measures achievable in the primary care setting. ${ }^{21}{ }^{22}$ Our findings are therefore pertinent to the population for which stepdown is recommended, and our management approach can be adopted easily by primary care teams, which are responsible for the care of most asthma patients. We recruited from six health board areas, across a wide range of deprivation categories and rural and urban settings. We believe therefore that our findings can be generalised to the population at large. As our study was limited to patients receiving high doses of inhaled corticosteroids our findings may not be reproducible in patients with milder disease who receive lower doses.

Not all patients allocated to the stepdown regimen received a reduction in their dose of inhaled corticosteroids. However, sufficient numbers (83\%) received the intervention for the study to be valid, and the inclusion of patients who did not makes this a true intention to treat analysis, reflecting the reality of managing this group of patients in practice. We included smokers in our study, a group often excluded from trials but estimated to represent up to $30 \%$ of adult asthma patients. ${ }^{23}$ A proportion of the smokers may have had mixed disease with an element of irreversible airflow obstruction, but any influence this may have had on the results is likely to be minimal because of the small numbers involved.

Previous research has shown that the dose of inhaled corticosteroids can be reduced in patients with mild disease. ${ }^{5}$ Results from other trials show that it should also be possible to reduce the dose of inhaled corticosteroids in moderate or severe asthma without jeopardising control. ${ }^{67}$ However, these studies have been limited by short term follow up and have used an "open label" design for reducing the dose of inhaled corticosteroids. As the stepdown approach to using

\section{What is already known on this subject}

Asthma management guidelines recommend a stepwise reduction in the dosage of inhaled corticosteroids for patients with well controlled asthma

Research evidence shows that such a reduction can be achieved in patients with mild disease, in the short term, or with the addition of other antiasthma treatments

The clinical implications of stepping down inhaled corticosteroids have not previously been tested by means of a randomised controlled trial over the longer term or in patients with moderate to severe disease

\section{What this study adds}

Adopting a stepdown approach to the use of high dose corticosteroids in patients with chronic stable asthma can lead to a significant reduction in the daily dose of inhaled corticosteroids without compromising asthma control
Table 4 Corticosteroid dosage in the two groups

\begin{tabular}{lccc} 
Mean (SD) dose of drug & Stepdown group & Control group & Difference (95\% CI) \\
\hline Oral corticosteroid*: & $(\mathrm{n}=130)$ & $(\mathrm{n}=129)$ & N/A \\
\hline Yearly $(\mathrm{mg})$ & $117(215)$ & $109(275)$ & N/A \\
\hline Inhaled corticosteroidt: & $(\mathrm{n}=120)$ & $(\mathrm{n}=123)$ & \\
\hline Yearly $(\mathrm{mg})$ & $390(189)$ & $517(231)$ & $-127(-180$ to -74$)$ \\
\hline Monthly $(\mathrm{mg})$ & $32(16)$ & $42(19)$ & $-10(-15$ to -6$)$ \\
\hline Daily $(\mu \mathrm{g})$ & $1067(518)$ & $1415(631)$ & $-348(-494$ to-202)
\end{tabular}

*Median in both groups $=0 \mathrm{mg}$. Significance test is Wilcoxon, $\mathrm{P}=0.252$.

†Conversion rate of $1 \mathrm{mg}$ fluticasone propionate $=2 \mathrm{mg}$ beclomethasone dipropionate used for calculation. Significance test is $t$ test, $\mathrm{P}=<0.001$.

inhaled corticosteroids in asthma has been adopted into international asthma guidelines largely as a result of expert opinion our study provides valuable evidence in support of this management strategy.

Over the one year period, participants in the stepdown group received, on average, $348 \mu \mathrm{g}(25 \%)$ less inhaled beclomethasone dipropionate per day than controls, and the use of oral corticosteroids did not differ significantly between the two groups. This finding shows that a stepdown approach to inhaled corticosteroids can reduce the risk of steroid related side effects in this group of patients.

We thank GlaxoSmithKline UK for donating the study inhalers; Annemarie Crowe, Adele Johnstone, and colleagues in the pharmacy department, Gartnavel General Hospital, Glasgow for blinding and packaging the study inhalers; Karon Carson and Joyce Thompson for data collection; West of Scotland (WestNet) and Forth Valley Research Networks for their help with practice recruitment; all general practitioners who participated in the study and their practice staff.

Contributors: GH contributed to the study design, execution, and interpretation, and wrote the first and final drafts of the paper. AM performed the data analysis and contributed to the study design and execution, and writing the paper. ST, SW, and IF all contributed to the study design, execution and interpretation, and writing the paper. NT was responsible for the study conception and design, contributed to the study execution and interpretation and writing the paper, and is the guarantor. Funding: NHS R\&D Programme on Asthma Management. Competing interests: NCT has been reimbursed by AstraZeneca (AZ), GlaxoSmithKline (GSK), and Schering Plough (SP), the manufacturers of budesonide, beclomethasone and fluticasone, and mometasone, respectively, for attending several conferences and has acted as a consultant to GSK and Altana. His department has received research funds for clinical trials from AZ, GSK, Novartis, and Merck; SFW has received fees for speaking, chairing, or advising from GSK, AZ, SP, and Aventis; IF has received research funding and committee honorariums from GSK and a committee honorarium and speaking fee from AZ.

Ethical approval was granted by the multicentre research ethics committee for Scotland and appropriate local research ethics committees.

Barnes PJ, Pedersen S, Busse WW. Efficacy and safety of inhaled corticosteroids: new developments. Am I Respir Crit Care Med 1998; 157(suppl):S1-S53.

2 British Guidelines on the Management of Asthma. Thorax 2003;58(suppl 1):S1-S96.

3 Global Initiative for Asthma. Global strategy for asthma management and prevention. Bethesda (MD): NHLBI/WHO Workshop Report 1995. (Publication no 95-3659.)

4 Lipworth BJ. Systemic adverse effects of inhaled corticosteroid therapy. Arch Intern Med 1999;159:941-55.

5 Haahtela T, Jarvinnen M, Kava T, Kiviranta K, Sirkka K, Lehtonen K, et al. Effects of reducing or discontinuing inhaled budesonide in patients with mild asthma. N Engl J Med 1994;331:700-5.

6 Leuppi J, Salome CM, Jenkins CR, Anderson SD, Xuan W, Marks GB, et al. Predictive markers of asthma exacerbation during stepwise dose reduction of inhaled corticosteroids. Am I Respir Crit Care Med 2001;163:406-12.

7 Wilding P, Clark M, Coon JT, Lewis S, Rushton L, Bennett J, et al. Effect of long term treatment with salmeterol on asthma control: a double blind randomised crossover study BMJ 1997;314:1441-6.

8 Lemanske RF Jr, Sorkness CA, Mauger EA, Lazarus SC, Boushey HA, Fahy JV, et al. Inhaled corticosteroid reduction and elimination in 
patients with persistant asthma receiving salmeterol: a randomised controlled trial. JAMA 2001;285:2594-603.

9 American Thoracic Society. Standards for the diagnosis and care of patients with chronic obstructive pulmonary disease (COPD) and asthma. Am Rev Respir Dis 1987;136:225-34.

10 Rimmington LD, Aronoffsky L, Mowatt A, Whaburton E, Ryland I, Pearson MG. Use of a simple patient focussed asthma morbidity score. Eur Respir J 1997;11:1289.

11 Dekker FW, Dieleman FE, Kaptein AA, Mulder JD. Compliance with pulmonary medication in general practice. Eur Respir J 1993;6:890.

12 Jones PW, Quirk FH, Baveystock CM, Littlejohns P. A self-complete measure of health status for chronic airflow limitation. Am Rev Respir Dis 1992;145:1321-7.

13 The EuroQol Group. EuroQol-a new facility for the measurement of health-related quality of life. Health Policy 1990;16:199-208.

14 Fabbri L, Burge PS, Croonenborgh L. Comparison of fluticasone propionate with beclomethasone dipropionate in moderate to severe asthma treated for one year. Thorax 1993;48:817-23.

15 Woolcock AJ, Lundback B, Ringdal N, Jacques LA. Comparison of addition of salmeterol to inhaled steroids with doubling of the dose of inhaled steroids. Am J Respir Crit Care Med 1996;153:1488.
16 Wong CA, Walsh LJ, Smith CJP, Wisnieswski AF, Lewis SA, Hubbard R, et al. Inhaled corticosteroid use and bone-mineral density in patients with asthma. Lancet 2000;355:1399-403.

17 Gershman NH, Wong HH, Liu JT, Fahy JV. Low and high-dose fluticasone propionate in asthma: effects during and after treatment. Eur Respir J 2000;15:11-8

18 Holt S, Suder A, Weatherall M, Cheng S, Shirtcliffe P, Beasley R. Dose-response relation of inhaled fluticasone propionate in adolescents and adults with asthma: meta-analysis. BMJ 2001;323:253-6.

19 Bousquet J, Ben-Joseph R, Messonnier M, Alemao E, Gould AL. A metaanalysis of the dose-response relationship of inhaled corticosteroids in adolescents and adults with mild to moderate persistent asthma. Clin Ther 2002;24:1-20.

20 McMahon AD Study control, violators, inclusion criteria and defining explanatory and pragmatic trials. Stat Med 2002;21:1365-76.

21 Roland M, Torgerson DJ. Understanding controlled trials: What are pragmatic tials? BMj $1998,916.285$.

22 Tattersfield AE, Harrison TW. Step 3 of the asthma guidelines. Thora 1999;54:753-4.

23 Althuis MD, Sexton M, Prybylski D. Cigarette smoking and asthma symptom severity among adult asthmatics. J Asthma 1999;36:257-64.

(Accepted 24 March 2003) 